\title{
IASPM@Journal
}

\section{Grunge: Music and Memory}

\author{
Catherine Strong \\ Farnham, Surry: Ashgate Publishing Ltd, 2011 \\ ISBN: 9781409423768 (HB) \\ RRP: $£ 55.00$
}

\author{
Lauren Istvandity \\ Griffith University, Australia \\ lauren.istvandity@griffithuni.edu.au
}

Upon hearing the word "grunge" most people under 50 would describe images of flannel, eyeliner, and shaggy hair coupled with attitudinal apathy. Maybe that's what they know to be true, or perhaps it's what the media has led them to believe. This is the starting point for Grunge: Music and Memory which, as part of its quest to triangulate the relationship between culture, memory and power, contrasts the ways in which grunge music has been constructed through various media forms versus the public's collective memory.

Based on author Catherine Strong's doctoral thesis, the book explores the elements and perspectives of how grunge has been remembered by active participants in 1990s grunge culture, and how the discourses of grunge challenged societal norms in the vigorous power-play between the emergence and co-option of popular culture. Strong compiled data from the media - principally from the UK magazine New Musical Express (NME) - to map journalists' reactions, from the recognition of grunge to its demise soon after Kurt Cobain's death, and beyond this in anniversary specials occurring periodically in print media (e.g. Rolling Stone, Record Collector, Mojo, and Spin). The ideals and narratives found here are compared to accounts from a sample of Australian adults who identify as fans of grunge, and it is here that an interesting contrast is identified.

After setting these foundations in the introductory chapter, Chapter 2 comprises a dense literature survey pared into two sections. The first section does two things: at once it situates grunge literature in the greater field of popular music studies while also describing what the academic writing on grunge has (or has forgotten) to say on the subject. This extends to concepts such as authenticity, commercialism and politics and the ways in which they conflicted with the ideology of grunge culture. The second section gives a brief overview of several popular theories and definitions of collective memory, through which Strong defines the applications of and exceptions to her own use of the term "collective memories" for the remainder of the book.

The rise and fall of grunge as presented in the media is considered in Chapter 3 , relating specifically to the case of Nirvana who have been promoted by various media sources as the most successful grunge band, due to their apparent overnight success as well as the prominent death of lead singer Kurt Cobain, among other reasons noted in this chapter. The cultural location of grunge is framed by Strong through the use of Pierre Bourdieu's field theory, which conceptualises tastes and cultures in a way that is 
relatable to societal structures. In doing this Strong shows how the rise and fall of Nirvana can be thought of as part of a natural cycle of replacing aging culture. The second half of this chapter is devoted to mapping journalistic accounts of grunge in NME (1990-1994), anniversary publications in print media, and movies and documentaries. In this critique, Strong notes how NME identified, encouraged and then "killed off" (p. 49) grunge due to its coverage conveying either more or less favourable overtones.

The most intriguing part of this study I feel is captured in Chapter 4, in which Strong reveals some of the responses given by her sample of self-identified grunge fans. Here, definitions of memory that are provided by the media are contrasted with those given by respondents. It is noted that media definitions were formed at the height of grunge culture, and those given by interviewees are more or less current. This is an unavoidable hurdle however it still yields a valuable comparison. Strong shows that while most accounts given by respondents were mediated rather than based on firsthand experience, there were notable differences between what was presented by the media and how this information has been interpreted. The only problem that comes up with this chapter is that perhaps the intersection between individual accounts, and therefore autobiographical memories, with that of the collective could be given more attention seeing as both minority and majority views are considered in this study.

Chapters 5 and 6 discuss aspects of grunge's legacy. As mentioned, the media engages in anniversaries (typically in increments of 10 years) relating to grunge, and in this book the specific anniversary to receive most attention relates to the death of Kurt Cobain. Chapter 5 describes the activities and media attention surrounding this anniversary, showing that while at a state level the acclamation of a rebellious figure is not condoned the media is nonetheless responsible for perpetuating certain narratives about Cobain as the figurehead of grunge. Such journalistic claims that he was a supreme, godlike, tragic artist destined for greatness are contrasted cleverly by Strong with accounts from respondents who described Cobain as an unexceptional, regular guy. Chapter 6 side steps the traditional ideals of grunge as described in the preceding chapters, taking a moment to discuss the role of female artists in grunge. While allfemale or near-all-female grunge bands did exist at grunge's peak, they have been all but left out in the accounts of interviewees. Strong goes on to compare female respondent's opinions on Courtney Love and her message of gender equality as portrayed in the media, concluding that this discourse was received by only a small percentage of study participants.

By way of pulling all this information together, Strong considers the use of common labels "Generation X", "The 90s", and "Youth" as frames for understanding grungerelated memories. Through a discussion of these terms, she finds that none of them are suitable to identify the public that experienced the grunge phenomenon. Strong therefore suggests that due to various factors, the grunge cohort does not have "a strong sense of itself" (p. 154).

Grunge: Music and Memory challenges typical academic discourses about grunge music and its place in popular memory. Strong offers interesting discussions on the role of media, mediation and memory, as well as the ways in which grunge as a cultural product is situated within a larger social hierarchy. The book's only downfall may be its lack of accessibility to non-academic readers. It is clear from the writing style that this book has undergone conversion from a thesis and as such the language would be most suitable for postgraduate students or academics but would be tough going for undergraduates or non-academics. Overall this book makes headway in academic writing on grunge, leaving the door ajar for both readers and researchers to think more critically about the roles that media and memory might play in shaping popular culture. 